\title{
Digital Pain Mapping and Tracking in Patients With Chronic Pain: Longitudinal Study
}

Maria Galve Villa ${ }^{1}$, MSc; Thorvaldur S Palsson ${ }^{2}$, PhD; Albert Cid Royo ${ }^{1}, \mathrm{MSc}$; Carsten R Bjarkam ${ }^{3}$, PhD; Shellie A Boudreau ${ }^{1}, \mathrm{PhD}$

${ }^{1}$ Center for Neuroplasticity and Pain, Center for Sensory Motor Interaction, Department of Health Science and Technology, Faculty of Medicine, Aalborg University, Aalborg, Denmark

${ }^{2}$ Center for Sensory Motor Interaction, Department of Health Science and Technology, Faculty of Medicine, Aalborg University, Aalborg, Denmark

${ }^{3}$ Department of Neurosurgery, Institute of Clinical Medicine, Aalborg University Hospital, Aalborg, Denmark

\section{Corresponding Author:}

Shellie A Boudreau, PhD

Center for Neuroplasticity and Pain, Center for Sensory Motor Interaction, Department of Health Science and Technology

Faculty of Medicine

Aalborg University

Frederik Bajers Vej 7D

Aalborg, 9200

Denmark

Phone: 4599409829

Email: sboudreau@hst.aau.dk

\begin{abstract}
Background: Digital pain mapping allows for remote and ecological momentary assessment in patients over multiple time points spanning days to months. Frequent ecological assessments may reveal tendencies and fluctuations more clearly and provide insights into the trajectory of a patient's pain.

Objective: The primary aim of this study is to remotely map and track the intensity and distribution of pain and discomfort (eg, burning, aching, and tingling) in patients with nonmalignant spinal referred pain over 12 weeks using a web-based app for digital pain mapping. The secondary aim is to explore the barriers of use by determining the differences in clinical and user characteristics between patients with good (regular users) and poor (nonregular users) reporting compliance.

Methods: Patients ( $\mathrm{N}=91 ; \mathrm{n}=53$ women) with spinal referred pain were recruited using web-based and traditional in-house strategies. Patients were asked to submit weekly digital pain reports for 12 weeks. Each pain report consisted of digital pain drawings on a pseudo-three-dimensional body chart and pain intensity ratings. The pain drawings captured the distribution of pain and discomfort (pain quality descriptors) expressed as the total extent and location. Differences in weekly pain reports were explored using the total extent (pixels), current and usual pain intensity ratings, frequency of quality descriptor selection, and Jaccard similarity index. Validated e-questionnaires were completed at baseline to determine the patients' characteristics (adapted Danish National Spine Register), disability (Oswestry Disability Index and Neck Disability Index), and pain catastrophizing (Pain Catastrophizing Scale) profiles. Barriers of use were assessed at 6 weeks using a health care-related usability and acceptance e-questionnaire and a self-developed technology-specific e-questionnaire to assess the accessibility and ease of access of the pain mapping app. Associations between total extent, pain intensity, disability, and catastrophizing were explored to further understand pain. Differences between regular and nonregular users were assessed to understand the pain mapping app reporting compliance.

Results: Fluctuations were identified in pain reports for total extent and pain intensity ratings $(P<.001)$. However, quality descriptor selection $(P=.99)$ and pain drawing $(P=.49)$, compared using the Jaccard index, were similar over time. Interestingly, current pain intensity was greater than usual pain intensity $(P<.001)$, suggesting that the timing of pain reporting coincided with a more intense pain experience than usual. Usability and acceptance were similar between regular and nonregular users. Regular users were younger $(P<.001)$ and reported a larger total extent of pain than nonregular users $(P<.001)$.
\end{abstract}

Conclusions: This is the first study to examine digital reports of pain intensity and distribution in patients with nonmalignant spinal referred pain remotely for a sustained period and barriers of use and compliance using a digital pain mapping app. Differences in age, pain distribution, and current pain intensity may influence reporting behavior and compliance. 
(J Med Internet Res 2020;22(10):e21475) doi: 10.2196/21475

\section{KEYWORDS}

eHealth; medical illustrations; pain perception; mHealth; pain measurement; disease progression; patient-reported outcome measures; musculoskeletal pain; mobile phone; surveys and questionnaires; pain management

\section{Introduction}

\section{Background}

The term spinal pain refers to pain in the cervical, thoracic, and low back areas of the spine [1,2]. Spinal pain can remain localized to the spine and refer to other areas. Cervical and thoracic spinal pain may refer to one or both the upper limbs [2], whereas low back spinal pain may refer to one or both of the lower limbs [2]. Chronic spinal pain is a common reason for clinical consultation $[3,4]$ with an increasing prevalence [5,6] and associated high levels of disability [7].

Pain is a subjective sensory and emotional experience [8], and patients' self-reported measures of pain, such as pain intensity and quality descriptors, are common during pain assessment [9]. In addition, self-reports of pain distribution can improve the understanding of pain mechanisms [10-12]. Therefore, more efficient patient-clinician communication is paramount to optimize pain management. Traditionally, numerical rating scales capture pain intensity, whereas pain drawings capture pain distribution that is expressed by area (extent) and location [13].

Among the self-reported methodologies, ecological (from the patients' environment) momentary (in real time) assessment (EMA) methods can help to repeatedly collect information about the patient's pain condition $[14,15]$. In the clinical pain field, EMA methods can be used to minimize pain recall bias and assess pain within the patients' real-world context $[14,16]$ to provide detailed spatiotemporal information and support pain management [12,17-21]. For example, repeated pain intensity reports of patients with musculoskeletal spinal pain may present a stable or fluctuating temporal pattern [22-27]. Similarly, spatiotemporal patterns of pain may present a stable (localized or widespread) or a variable course [28,29]. However, there is little knowledge about the relationship between the course of pain intensity and extent.

Digital biomarkers are defined as objective and quantifiable physiological and behavioral data acquired and measured using digital devices, such as smartphones, tablets, or computers. Thus, digital pain mapping can acquire time-stamped digital pain biomarkers (pain intensity, distribution, and quality). When acquired over multiple time points, a more detailed overview of a patient's pain experience can be achieved, thereby improving the clinician's understanding of the patient's pain [12].

The feasibility of health apps is mostly dependent on its usability and reporting compliance [30,31]. Usability is a broad term that defines the appropriateness of a technology to fit its purpose [32]. A good compliance rate ensures that the requested information is collected [33-38]. However, little is known about the influence of user characteristics and symptom severity on compliance.

\section{Objectives}

This feasibility study aims to map and track pain intensity (current and usual), distribution (extent and location), and quality of pain and discomfort in patients with nonmalignant spinal referred pain for a duration of 12 weeks using a digital pain mapping app. The secondary aim is to determine the barriers to use and individual and clinical factors influencing a patient's pain reporting compliance using the digital mapping app.

The study aims to address 3 main hypotheses: (1) fluctuations in pain intensity, distribution, and quality over 12 weeks would be identified; (2) pain extent would be associated with current pain intensity and levels of disability; and (3) better reporting compliance would be more likely in patients with more severe pain symptoms.

\section{Methods}

\section{Overview}

This web-based prospective observational cohort study recruited people with nonmalignant spinal referred pain (somatic and radicular) and asked them to submit a weekly pain report for 12 weeks using a web-based pain mapping app. At baseline, all participants completed standardized e-questionnaires about demographics, primary pain site (cervical and thoracic pain or low back pain), disability, and pain catastrophizing. Six weeks into the study, patients were invited to participate in a battery of health care-related usability and acceptance (HUX) e-questionnaire and a self-developed technology-specific e-questionnaire to gain insight into the appropriateness and ease of use of the pain mapping app.

\section{Participants and Recruitment}

The inclusion criteria were kept broad to obtain a general impression of the weekly differences in pain intensity, extent, and quality in patients with nonmalignant spinal referred pain. Men and women (aged 18-85 years) living in Denmark and able to communicate in Danish or English were recruited. Pregnant or breastfeeding women and people with drug abuse and addiction problems were not included. People with a cognitive deficiency, those who lack necessary computer skills (self-assessment or inability to create a password), and/or those who do not have regular internet access were excluded from the study.

In total, 2 recruitment strategies were designed. The traditional strategy consisted of recruiting patients referred to the Neurosurgical Department at Aalborg University Hospital (Denmark). The web-based recruitment strategy consisted of posting a 1-min video on social media platforms (Facebook, LinkedIn, and Twitter) with a call-to-action requesting those interested in taking part in the study to contact the researchers directly via email. Screening was carried out via email 
correspondence. Additional screening for all patients was carried out by phone interviews, where information about medical history, diagnoses, and current treatment was collected. The patients' pain management was not monitored or affected during the study.

Patients received detailed information about the study via email, including technical information about registration to the pain mapping app and how to complete the digital pain reports. Subsequently, the researcher (MG) emailed the link to the demographic questionnaire related to their primary pain site (cervical and thoracic or low back). The links to the remaining e-questionnaires (disability and pain catastrophizing) were emailed individually on completion of the previous questionnaire. Each questionnaire took 2 to $3 \mathrm{~min}$ to complete.

Furthermore, 6 weeks after the first pain report was submitted, patients completed HUX e-questionnaires, such as the System Usability Scale (SUS) [32] and the modified Technology Acceptance Model (mTAM) questionnaire [39] and a self-developed technology-specific questionnaire.

\section{Baseline Patient Profile}

Baseline e-questionnaires collected information about the patients' general demographics, walking distance ability, health and social information, disability, and pain beliefs. A maximum of 3 reminders were emailed to the patients, each 1 week apart. If a questionnaire was not completed following the 3 reminders, the patient received a final direct email reminder. Questionnaires were delivered using the SurveyXact software (Ramboll). Permission was obtained to use and adapt all the paper-format questionnaires to the electronic versions used in this study.

The general information questionnaire, adapted from the Danish National Spine Register's (DaneSpine) basic information questionnaire for degenerative spinal disorders, was used to collect information regarding demographics, walking distance ability, health, and social status. Disability was measured by the Oswestry Disability Index (ODI) in patients whose primary pain site was low back and by the Neck Disability Index (NDI) in patients whose primary pain site was the cervical or thoracic spine. The ODI and the NDI have been used since 1990 and are recommended tools for evaluating self-rated disability in spinal disorders [40,41]. The Pain Catastrophizing Scale (PCS) was used to evaluate pain-related catastrophizing thoughts. Catastrophizing is a negative anticipatory response associated with higher pain intensity $[42,43]$.

\section{Quantification of Pain Intensity, Extent, and Distribution Consistency}

Navigate Pain (Aglance Solutions) allows for the EMA of the temporal development of pain intensity and extent, thereby facilitating an objective and easy visualization of pain changes over time $[44,45]$. The web-based digital pain mapping app allows users to complete individual pain reports. The pain mapping app had a zoom feature and the option of moving the body chart on the screen to facilitate the visualization and capturing of pain. In each pain report, users indicated their pain area and location on a pseudo-three-dimensional body chart avatar in different views (anterior, posterior, lateral right, and lateral left) and provided a usual and a current pain intensity rating. Usual pain intensity was defined as the pain felt most of the time, whereas current pain intensity was defined as the pain experienced at the time of reporting.

Patients received an email with a link to create a password for accessing the pain mapping app free of charge. Patients used a computer mouse or a touch screen device (ie, smartphone or tablet) to report the distribution of pain and discomfort on a male or female body chart. Patients selected among 11 color-coded pain and discomfort quality descriptors: tingling, throbbing, stabbing, dull aching, numbness, itchy, electric, cold, burning, other, and the general descriptor pain. The number of pixels was extracted from the drawn areas in the body charts, including the different views, to quantify the total pain and discomfort extent (total extent). Only one pain report was used to determine the extent and distribution of pain and discomfort each week. If patients submitted more than one weekly pain report, the first pain report following the weekly reminder or the report closest to a 7-day interval was selected. Weekly pain intensity ratings were calculated using all reports for each week.

Patients rated their overall usual and current pain intensity using 2 electronic Color Analogue Scales (eCASs). The eCAS is a colored line (green, yellow, and red) accompanied by the words no pain, moderate pain, and severe pain [46,47].

The consistency of pain distribution may assist in a more objective decision-making process. To assess the consistency of pain and discomfort distribution, 1 pain drawing in the posterior view for each of the 12 weeks was extracted from the weekly pain reports. The similarity of degree of distribution among the weekly pain drawings was calculated and expressed using the Jaccard similarity coefficient, also known as the Jaccard index [48]. The Jaccard indices were calculated between consecutive pain drawings (week to week) during the 12-week period. A higher Jaccard index represents a greater pixel overlap between drawings and is a proxy measure to determine the degree of changes in the distribution (ie, combination of the location and area) of pain and discomfort between weekly pain reports $[11,12,48]$. Owing to the inconsistent use of the anterior and lateral body chart views, only the posterior view was used to calculate the Jaccard index. The posterior view was used in all the weekly pain reports and was found to be the most relevant view to capture changes in spinally referred pain.

\section{Assessment of Pain and Discomfort Quality Descriptors}

Pain and discomfort quality descriptors are clinically useful during the differential diagnosis process, especially for neuropathic pain [49-52]. The frequency of pain and discomfort quality descriptor selection was calculated by normalizing the number of times a quality descriptor was selected. Therefore, a selected descriptor was only accounted for once weekly for each patient.

\section{Health Care-Related Usability, Acceptance, and Technology-Specific Questionnaires}

To explore the barriers of use, patients who had completed at least one pain report at 6 weeks were deemed as users and invited to complete a battery of electronic questionnaires, including HUX questionnaires and a technology-specific questionnaire. The HUX questionnaires consisted of SUS and 
mTAM questionnaires to assess the usability and acceptance of the pain mapping app among patients.

The SUS is a simple 10-statement questionnaire evaluating the user experience before any discussion with the researcher. There are alternating positive and negative statements. The version used here replaced the term the product to the name of the digital body mapping software Navigate Pain. An SUS score over 68 is considered above average [32]. The Technology Acceptance Model (TAM) [39] was modified (mTAM) with the term digital body chart to describe the technology. The mTAM consisted of a total of 9 statements - 4 of these rated perceived usefulness and 5 rated perceived ease of use. Both questionnaires use a 5-point Likert scale, ranging from 1 for strongly disagree to 5 for strongly agree.

A Navigate Pain Specific (NPS) questionnaire was developed to examine user behavior, particularly accessibility and ease of access. Patients were asked to answer 5 questions. Of these questions, 2 questions assessed point of access to the mapping app (computer or laptop, tablet, or smartphone) and the access pathway to the pain mapping app (reminder email or direct URL link). One question used a 5-point Likert scale, ranging from 1 for very helpful to 5 for not at all helpful, to explore the helpfulness of the weekly pain report reminder. The last 2 questions also used a 5-point Likert scale, ranging from 1 for very easy to 5 for very difficult to assess the registration process and the general patients' perspective of ease of use.

\section{Differences Between Regular and Nonregular Users}

Patient characteristics were assessed in relation to pain reporting compliance. Regular users completed weekly pain reports, whereas nonregular users did not fulfill this criterion. In the NPS questionnaire, nonregular users received an additional question asking for reasons for the lack of regular pain reporting, such as "I didn't have time," "I forgot to do it," "I am in too much pain to do it," "I don't have pain," "I'm not interested in using Navigate Pain any more," and "Other."

\section{Statistical Analysis}

Descriptive statistics were used to describe demographics and baseline characteristics and quality descriptor selection. Data distribution was assessed with histograms and quantile-quantile plots for pain intensity ratings, total extent (pixels), and pain distribution (Jaccard index). For nonparametric data, Friedman tests were used to assess the pain intensity ratings (usual and current) and the total extent between weeks. A Wilcoxon signed-rank test was used to compare the differences between current and usual pain intensity ratings. The consistency of pain distribution was determined by comparing the Jaccard indices each week using a Friedman test. A logistic multiple regression analysis was carried out to explore the influence of reporting compliance on pain distribution consistency. A chi-square test was used to assess differences in weekly pain and discomfort quality descriptor selection during the 12 weeks.

Spearman correlation was used to determine the associations between the pain intensity ratings and the total extent for each patient and the baseline disability and PCS scores.

Mann-Whitney $U$ tests were used to examine the differences in baseline characteristics between regular users and nonregular users, such as age, gender, primary pain site, usual and current pain intensity, total extent, disability, PCS scores, and HUX and NPS questionnaire results. A chi-square test was used to explore recruitment differences between regular and nonregular users. A logistic multiple regression analysis was carried out to explore the probability of better reporting compliance in relation to the severity of the pain symptoms. The assessment of pain severity included current pain intensity ratings, extent of pain quality (posterior view) from the first submitted pain report, and baseline disability (ODI or NDI) scores.

Statistical analyses were performed using SPSS 25 (SPSS Statistics, 2018). The Jaccard indices were calculated using MATLAB R2017b (The MathWorks, Inc). Correlation coefficients, means, SD values, median, and IQR were reported where relevant. $P$ values of less than .05 were considered statistically significant, and Bonferroni adjustment was used in multiple analyses.

In Denmark, observational studies using surveys and questionnaires are not required to obtain ethical approval but are required to be registered with the Danish Data Protection Agency (journal numbers 2017-899/10-0159 and 2017-509-00011). This study adhered to ethical data privacy and storage General Data Protection Regulation requirements and was conducted according to the Declaration of Helsinki. The study is registered with ClinicalTrials.gov (NCT03926364).

\section{Results}

\section{Baseline Patient Profile}

A total of 91 patients (mean age 51.8, SD 13.5 years; 53 women) were willing to participate in the study. Recruitment methods included a traditional in-house strategy and a web-based strategy. Following screening and early dropouts, a total of 78 patients were recruited to participate in the study (Figure 1). Overall, 92\% (12/13) of the early dropouts were due to technical difficulties with creating a password that limited access to the pain mapping app. 
Figure 1. CONSORT (Consolidated Standards of Reporting Trials) flow diagram, showing the complete recruitment process.

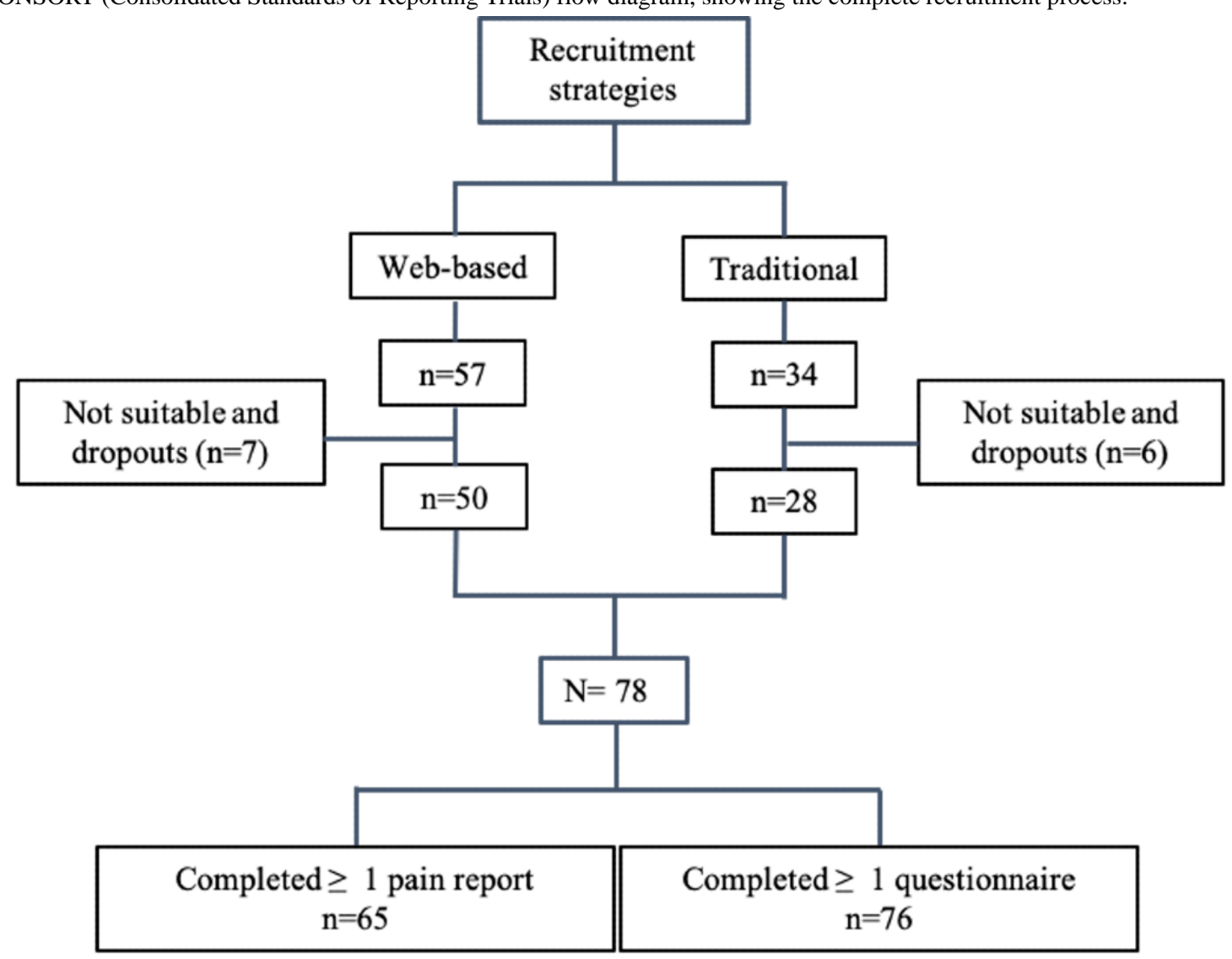

Overall, 64\% (50/78) of the participants were recruited using the web-based strategy. Only an age difference was identified between the patients recruited through the web-based strategy (mean age 48.7, SD 12.1 years) and the traditional in-house strategy (mean age 59.2, SD 13.4 years; $P<.001$ ).
A total of 3863 pain reports were submitted (mean 59, SD 66, per patient). All the patients recruited for this study had pain for longer than 6 months, with 79\% (60/76 completed questionnaires) of patients having pain for over 12 months (Table 1), thus fulfilling the criteria of chronic or persistent pain. Walking ability distance, disability, and catastrophizing scores at baseline are shown in Table 2. 
Table 1. Self-reported patients' baseline characteristics. ${ }^{\text {a }}$

\begin{tabular}{|c|c|c|}
\hline \multirow[t]{2}{*}{ Demographics } & \multicolumn{2}{|l|}{ Values } \\
\hline & $\mathrm{n}(\%)$ & Mean (SD) \\
\hline Age (years) & $76(100)$ & $51.78(13)$ \\
\hline \multicolumn{3}{|l|}{ Gender } \\
\hline Male & $24(32)$ & $\mathrm{N} / \mathrm{A}^{\mathrm{b}}$ \\
\hline Female & $52(68)$ & N/A \\
\hline \multicolumn{3}{|l|}{ Primary pain site } \\
\hline Cervical and thoracic & $17(22)$ & N/A \\
\hline Low back & $59(78)$ & N/A \\
\hline BMI $\left(\mathrm{kg} / \mathrm{m}^{2}\right)$ & 76 (100) & $27.69(5.3)$ \\
\hline Regular smokers & $10(12)$ & N/A \\
\hline Regular alcohol intake & $21(27)$ & N/A \\
\hline Units per week & N/A & $8.3(6.3)$ \\
\hline \multicolumn{3}{|l|}{ Current social history } \\
\hline Retired due to spinal pain & $19(25)$ & N/A \\
\hline Currently on sick leave & $19(25)$ & N/A \\
\hline \multicolumn{3}{|l|}{ Pain duration } \\
\hline Between 3-12 months & $16(21)$ & N/A \\
\hline Between 12-24 months & $9(12)$ & N/A \\
\hline More than 24 months & $51(67)$ & N/A \\
\hline Regular analgesia intake & $43(75)$ & N/A \\
\hline Morphine & $22(39)$ & N/A \\
\hline \multicolumn{3}{|l|}{ Self-reported diagnoses } \\
\hline Number of patients & $61(80)$ & N/A \\
\hline Discus prolapse or protrusion & $28(63)$ & N/A \\
\hline Degenerative changes & $14(32)$ & N/A \\
\hline Nonspecific & $14(32)$ & N/A \\
\hline Spinal stenosis & $13(30)$ & N/A \\
\hline Modic changes & $10(23)$ & N/A \\
\hline Spondylosis & $7(9)$ & N/A \\
\hline Scoliosis & $6(8)$ & N/A \\
\hline Spondylolisthesis & $2(3)$ & N/A \\
\hline Hypermobility & $1(1)$ & N/A \\
\hline Chronic pelvic pain & $1(1)$ & N/A \\
\hline \multicolumn{3}{|l|}{ Past medical history } \\
\hline Cardiac condition & $4(5)$ & N/A \\
\hline Neurological condition & $8(10)$ & N/A \\
\hline Cancer & $0(0)$ & N/A \\
\hline Other (painful condition) & $20(26)$ & N/A \\
\hline Other (affecting mobility) & $17(22)$ & N/A \\
\hline \multicolumn{3}{|l|}{ Previous spinal surgery } \\
\hline Once & $11(15)$ & N/A \\
\hline
\end{tabular}




\begin{tabular}{lll}
\hline Demographics & Values & Mean (SD) \\
\hline Twice & $\mathrm{n}(\%)$ & N/A \\
More than twice & $5(7)$ & N/A \\
\hline
\end{tabular}

${ }^{\mathrm{a}}$ The self-reported diagnoses include all the diagnoses reported by the patients.

${ }^{\mathrm{b}}$ N/A: not applicable.

Table 2. Baseline walking distance ability, disability, and catastrophizing scores.

\begin{tabular}{|c|c|c|}
\hline \multirow[t]{2}{*}{ Walking distance and disability } & \multicolumn{2}{|l|}{ Values } \\
\hline & $\mathrm{n}(\%)$ & Mean (SD) \\
\hline \multicolumn{3}{|l|}{ Walking distance ability } \\
\hline$<100 \mathrm{~m}$ & $9(12)$ & $\mathrm{N} / \mathrm{A}^{\mathrm{a}}$ \\
\hline $100-150 \mathrm{~m}$ & $12(16)$ & N/A \\
\hline $0.5-1 \mathrm{~km}$ & $7(10)$ & N/A \\
\hline More than $1 \mathrm{~km}$ & $48(62)$ & N/A \\
\hline Oswestry Disability Index & $46(78)$ & $35.16(15.9)$ \\
\hline Minimal disability & $11(24)$ & N/A \\
\hline Moderate disability & $19(41)$ & N/A \\
\hline Severe disability & $15(33)$ & N/A \\
\hline Crippled & $1(2)$ & N/A \\
\hline Neck Disability Index & $19(100)$ & $34.7(19.9)$ \\
\hline No disability & $0(0)$ & N/A \\
\hline Mild disability & $3(16)$ & N/A \\
\hline Moderate disability & $4(21)$ & N/A \\
\hline Severe disability & $3(16)$ & N/A \\
\hline Complete disability & $9(47)$ & N/A \\
\hline \multicolumn{3}{|l|}{ Catastrophizing beliefs } \\
\hline Pain Catastrophizing Scale & $51(67)$ & $21.92(12.3)$ \\
\hline Rumination & N/A & $7.4(4.7)$ \\
\hline Magnification & N/A & $4.11(3.06)$ \\
\hline Helplessness & N/A & $10.41(12.3)$ \\
\hline Total score $>30$ & $15(20)$ & N/A \\
\hline
\end{tabular}

${ }^{\mathrm{a}} \mathrm{N} / \mathrm{A}$ : not applicable.

\section{Quantification of Pain Intensity, Total Extent, and Distribution Consistency}

Current pain intensity ratings (median 6.3, IQR 4.5) were greater than usual pain intensity ratings (median 5.4, IQR 4.0; $\mathrm{Z}=-18.0$; $P<.001)$ when compared over the 12 weeks. Furthermore, fluctuations were identified in terms of usual pain intensity ratings $\left(\chi_{11}^{2}=145.3 ; P<.001\right)$, current pain intensity ratings $\left(\chi_{11}^{2}=105.7\right.$; same $\left.P<.001\right)$, and total extent $\left(\chi_{11}^{2}=48.7 ; P<.001\right)$ over the 12 weeks (Figure 2). Comparisons of subsequent pain drawings showed similar Jaccard indices $(P=.52)$ for the study cohort. The logistic regression model was not statistically significant $\left(\chi_{11}^{2}=8.1 ; P=.70\right)$. 
Figure 2. Median (IQR) pain and discomfort extent (A) and usual (B) and current (C) pain intensity ratings, increased and decreased as a group (n=65), in comparison with baseline and throughout the 12 weeks. The lower and upper quartiles, representing observations between the 25 th and 75 th percentile range, show the median for a month. The whiskers are drawn down to the 10th percentile and up to the 90th. Points below and above the whiskers are drawn as individual dots. $* P<.001$ adjusted for multiple comparisons. NRS: numerical rating scale.
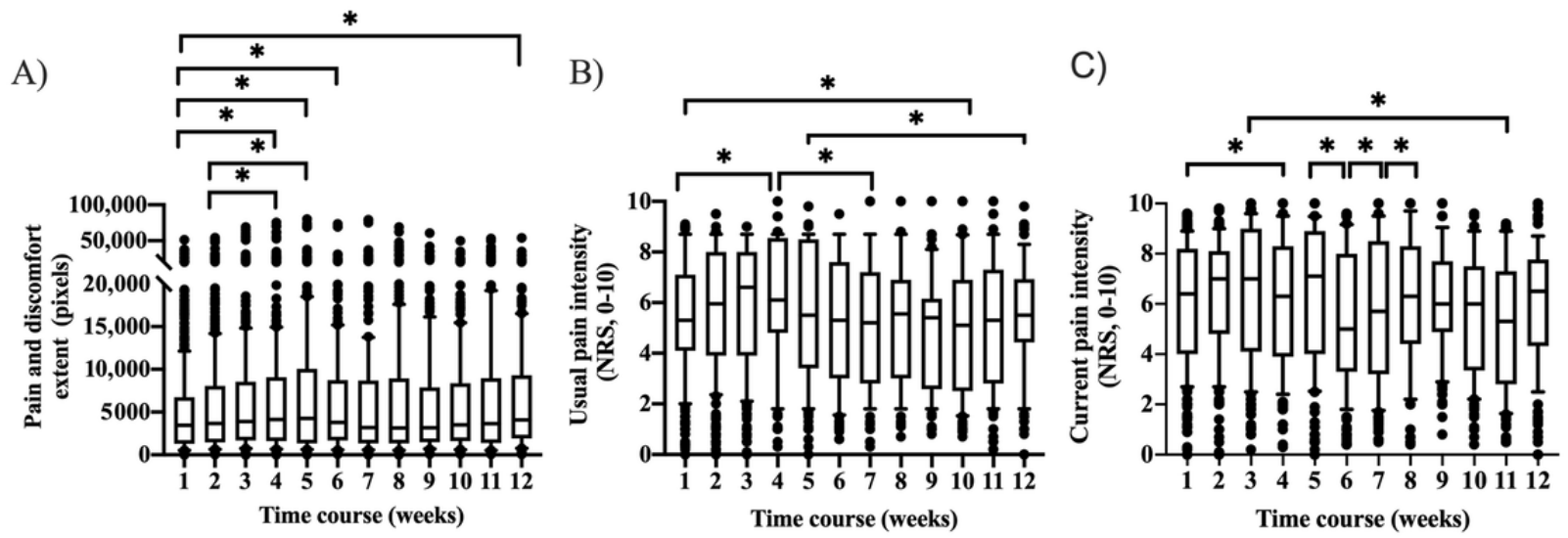

\section{Frequency of Pain and Discomfort Descriptors}

A chi-square test revealed that the selection of quality

3). However, individual variations in pain and discomfort quality descriptors remained stable over the 12 weeks $(P=.99$; Figure

Figure 3. The most frequently selected pain and discomfort quality descriptors over 12 weeks were pain (39\%) and dull (20\%). The qualities numbness $(9 \%)$, burning $(8 \%)$, and stabbing $(6 \%)$ were also chosen frequently. The least frequently selected quality descriptors were throbbing $(3.2 \%)$, other $(2.8 \%)$, itchy $(0.8 \%)$, and cold $(0.4 \%)$.

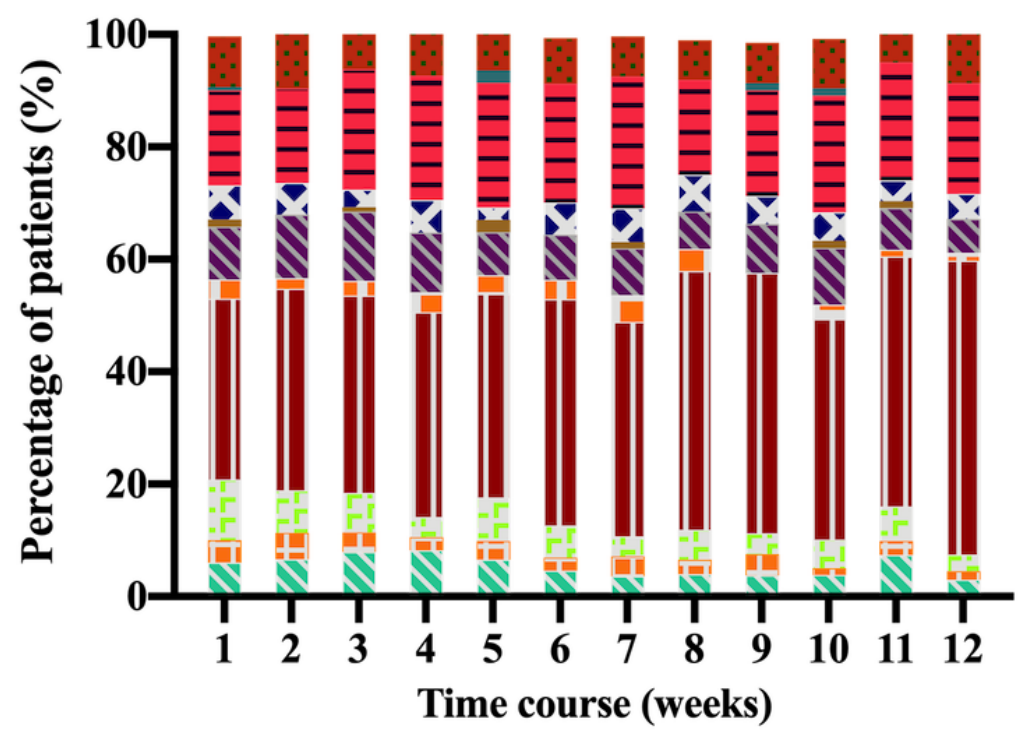

\begin{tabular}{|c|c|c|c|}
\hline av & Tingling & 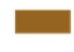 & Itchy \\
\hline DE⿱ & Throbbing & 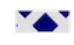 & Electric \\
\hline$F=r$ & Stabbing & 든 & Dull \\
\hline mI & Pain & & Cold \\
\hline 口i & Other & $\theta$ & Burning \\
\hline
\end{tabular}


Figure 4. Examples of individual pain reports illustrating fluctuations in pain and discomfort intensity, total extent, and quality, spanning 12 weeks. The red line represents the weekly average current pain intensity rating. The pain drawings were selected every second week to capture the general overview of the changes in pain and discomfort quality descriptors selection and the fluctuations in pain and discomfort extent over the 12 weeks. NRS: numerical rating scale.
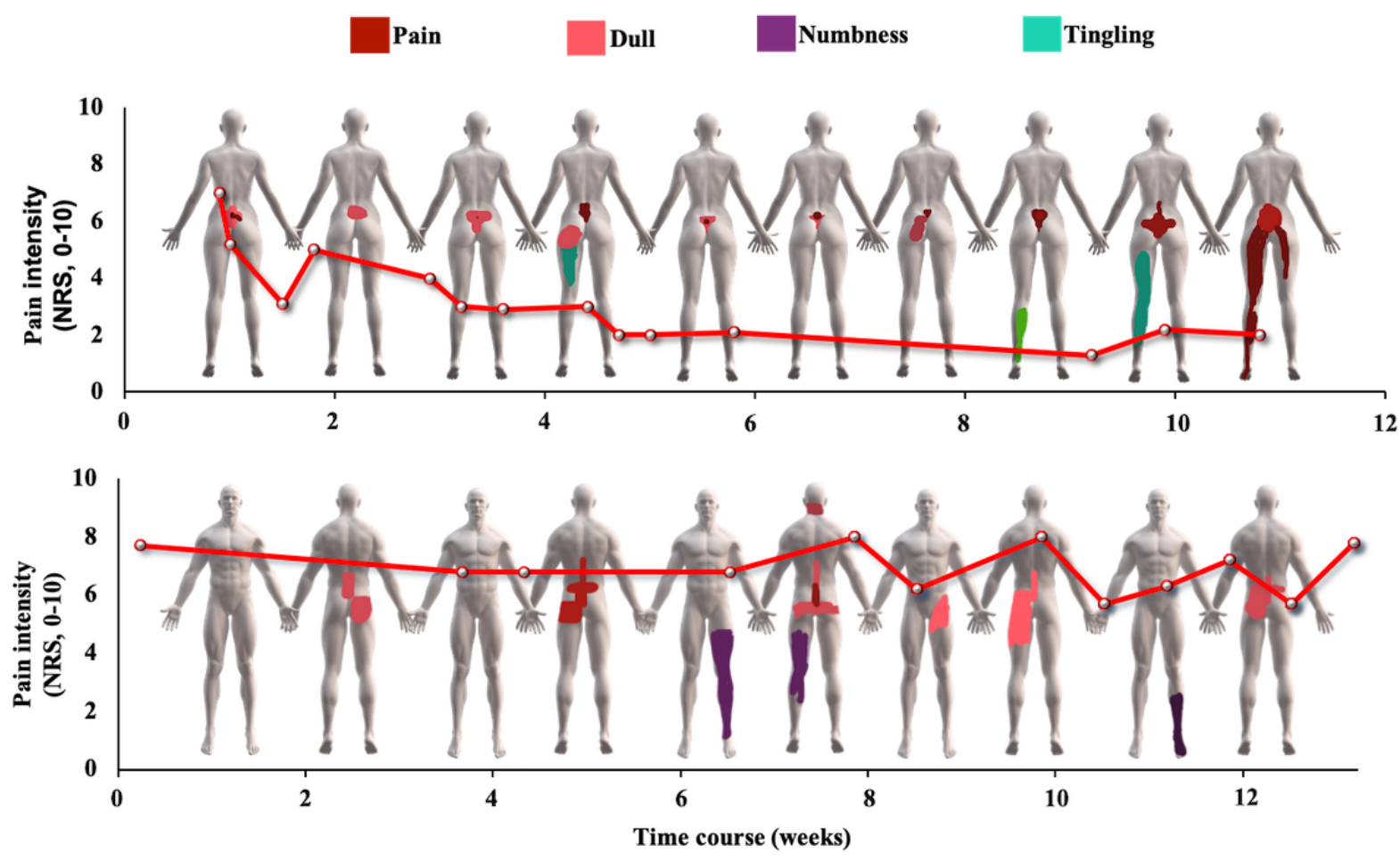

\section{Relationship Among Pain Intensity, Total Extent, Disability, and Pain Catastrophizing}

Usual and current pain intensities were associated with the total extent ( $r=0.23$ and $r=0.25$, respectively; $R^{2}=3 \% ; P<.001$ ). Disability, as rated by the ODI and NDI, was not associated with the current and usual pain intensities $(P=.29$ and $P=.09$, respectively), total extent $(P=.31)$, and pain catastrophizing $(P=.83)$. Similarly, pain catastrophizing was not associated with usual and current pain intensities $(P=.89$ and $P=.71$, respectively) and the total extent $(P=.29)$.

\section{Differences Between Regular and Nonregular Users}

Regular users ( $\mathrm{n}=35$; mean age 48.7, SD 11.2 years) and nonregular users ( $\mathrm{n}=30$; mean age 55.8, SD 15.3 years) differed in age $(P<.001)$. Interestingly, nonregular users had more intense current pain (median 6.4, IQR 3.2) than the regular users (median 6.1, IQR 5.1; $U=3306.7 ; P<.001$ ). However, regular users had a greater total extent (regular users 4063, IQR 8075.5; nonregular users 3221, IQR 4925.0; $U=2,775,320.5 ; P<.001$ ). In addition, $80 \%(28 / 35)$ of the regular users were recruited through the web, as opposed to $56 \%$ (17/30) of the nonregular $\left(\chi_{2}^{2}=28.9 ; P<.001\right)$. Current pain intensity, pain extent, and disability did not influence reporting compliance between regular and nonregular users $(P=.96)$.

\section{HUX Analyses}

HUX questionnaires were completed by $94 \%$ (33/35) of the regular and $73 \%(22 / 30)$ of the nonregular users. The total mean SUS score was 70, giving it a marginal usability score [53] with no difference between regular and nonregular users $(P=.45)$.
Regular users rated acceptable usability [54] with a mean SUS score of 71.5 points, whereas nonregular users rated marginal usability [53] with a mean SUS score of 68 points. There were no differences in mTAM scoring between the regular and nonregular users, with both groups having similar acceptance scores in each of the questionnaire statements $(P$ value range for each statement=.12-.97).

Of the regular users, $49 \%$ (17/35) accessed the pain mapping app from a computer or laptop and did not need the weekly reminder to submit the pain reports; nonregular users accessed the pain mapping app using a variety of devices, and $82 \%$ (20/30) depended on the weekly reminder to submit the pain reports. Furthermore, $45 \%(10 / 30)$ and $41 \%$ (9/30) of the nonregular users reported forgetfulness and other as the reasons for poor reporting compliance. The remaining $13 \%$ of nonregular users reported too much $(2 / 30)$ or no pain $(1 / 30)$. None of the patients selected I am not interested anymore or I did not have time.

Regular users rated the general use of the pain mapping app as easy or very easy $(15 / 35,45 \%$ and $8 / 30,27 \%$, respectively). Similarly, nonregular users rated the general use of the pain mapping app as easy and very easy $(11 / 30,50 \%$ and $4 / 30,18 \%)$, respectively. Only $6 \%(6 / 35)$ of the regular and $9 \%(2 / 30)$ of the nonregular users rated the general use of the pain mapping app as difficult. 


\section{Discussion}

\section{Principal Findings}

This is the first pragmatic observational study using a web-based app to map, track, and quantify pain and discomfort remotely in patients with nonmalignant spinal referred pain over a sustained period. The results show fluctuations in current and usual pain intensities over 12 weeks for the group of patients recruited for this study. In addition, the results show fluctuations in pain and discomfort extent (total extent) on a group level. However, the pain drawings and the quality descriptor selection remained consistent on a group level. HUX scores were similar between regular and nonregular users. The regular users were generally younger, had a greater total extent, and accessed the app differently than the nonregular users.

Fluctuations in current and usual pain intensities and in total extent occurred over the 12-week observation period, suggesting that spatiotemporal patterns of chronic spinal referred pain may increase and decrease over time. These fluctuations may be related to the heterogeneity of the study cohort in which participants had different primary pain sites, differences in pain management, and differences in reporting compliance. Thus, there is no rationale for why the group pain intensity and total extent varied on any given week over the 12-week observation period. An interesting observation in this study was that current pain intensity ratings were greater than usual pain intensity ratings, suggesting that patients completed pain reports when their pain was more intense than usual. The reasons for this reporting behavior are unclear and should be further explored. However, the difference between current and usual pain intensity ratings was small $(<1$ of 10$)$ and may not be clinically meaningful [54].

The selection of pain and discomfort quality descriptors remained consistent over time, which can be expected for a group with chronic pain. Interestingly, pain distribution also remained consistent. In this study, pain distribution consistency was calculated by comparing the similarity of consecutive weekly pain drawings. Therefore, the study's results do not imply that pain distribution was consistent throughout the 12 -week study period. It is possible that fluctuations in pain distribution may occur over longer periods (Multimedia Appendix 1). The Jaccard index has primarily been used to assess the ability of patients to reliably draw and redraw pain areas $[48,55]$. Therefore, the Jaccard index may only be appropriate to assess distribution consistency over shorter periods.

The study's findings align with previous studies [56-59] showing a weak and positive association between the pain intensities (usual and current) and the total extent. These results suggest that pain extent is related to pain intensity but do not explain the intensity variance. Therefore, capturing changes in clinical pain extent and distribution may add additional value to clinical interpretation.

The relationships of pain intensity and extent with disability and catastrophizing scores are contradictory. Similar to our study, studies on chronic low back pain $[60,61]$ and knee osteoarthritis [59] have shown that pain intensity and total extent were not associated with disability and pain catastrophizing. However, other studies have shown a positive relationship of the total extent with disability scores [11,62-66] and pain catastrophizing [43,62,67-69]. The relationship between catastrophizing and disability scores has been widely described in musculoskeletal shoulder and low back pain [70-72]. However, patients in our study reported high levels of disability but not high levels of catastrophizing, showing no association between disability and catastrophizing at baseline.

The HUX results demonstrated that the pain mapping app was considered a good pain communication tool by patients and therefore may be relevant for clinical practice. However, the HUX assessment failed to identify compliance differences, as represented by the similar results between regular and nonregular users.

Most of the regular users were recruited using the web-based strategy. Patients recruited through the web were younger (approximately by 3 years) and may already be more technically competent [73] than those recruited using the traditional strategy. A limited number of studies have assessed users' characteristics influencing the use and acceptance of pain technology [74]. Overall, regular users were younger (approximately by 7 years) and reported a larger pain extent than nonregular users, suggesting that reporting compliance of the pain mapping app may be based on an inherent need to communicate the pain extent [75]. Interestingly, the total extent differences between regular and nonregular users (approximately 850 pixels) represents a very small area on a pain drawing and may be insufficient to be clinically relevant. In a short period, the 7-year age gap between regular and nonregular users will become irrelevant as technical savviness increases among older adults [76]. Therefore, it is possible that in the future, only relevant baseline differences influencing compliance may be based on the recruitment method.

\section{Limitations}

EMA can induce bias because of the lack of standardization of pain reporting in terms of context (location and environment), timing, and frequency [15,77]. This study lacks contextual information about, for example, type or change in pain management and activity levels. Therefore, it is not known whether the fluctuations in total extent reporting may be due to a change in experienced pain or a change in the number of pain report submissions over time. Furthermore, fluctuations could also be due to a change in the drawing skills, as the patients' drawing confidence may have increased with repetition or even whether patients used different accessing devices affecting their technical skills.

Technical limitations influenced the total extent results and the distribution consistency index. First, the total extent may be overestimated, as it is the sum of all the quality descriptors used in a pain report. Second, only the Jaccard index was used as a measure of distribution consistency. Using one single index, the Jaccard index, to measure pain distribution consistency, carries potential risks for misinterpretation, as it will miss similarities between 2 pain drawings with equal pain areas but 
different locations, representing a small analytical variation, but with clinical implications.

Technical and interpretation barriers of use were identified. Technical barriers caused most of the early dropouts, likely because of using an old version of a browser, and may have biased the usability ratings. Interpretation barriers led to different drawing behaviors despite receiving the same instructions, highlighting different ways of understanding the provided pain reporting instructions or perceiving the individual pain experience (Multimedia Appendix 2).

\section{Future Perspectives}

The digital pain biomarkers acquired from the app can assist in a more objective diagnostic process and monitor the outcomes following treatment. An example of outcome monitoring could be useful following spinal surgery or a conservative approach, such as exercise therapy, where the pain mapping app can be used to monitor changes in pain intensity and referred arm and leg pain distribution [78]. New metrics for assessing consistency over a longer period may prove clinically valuable as fluctuating and stable pain reports may require different pain management approaches.

The usefulness and advantages of digital pain mapping to track digital pain biomarkers, combined with machine learning, have already revealed spatiotemporal patterns of pain and discomfort [10]. These patterns have the potential to become a game changer and may be able to predict those patients more likely to respond to treatments or assist in the prognosis of pain conditions [79].

\section{Conclusions}

This is the first study to remotely track pain intensity and distribution and examine barriers of use and compliance using a digital mapping pain app for a sustained period. Differences in age and pain distribution may influence reporting behavior and compliance and recruitment strategies that may play a role in the success of future web-based studies.

\section{Acknowledgments}

The authors thank Aalborg University (Talent Management Programme, 2016) and Tryg Fonden (109647) for providing funding. SB is part of the Center for Neuroplasticity and Pain, which is supported by the Danish National Research Foundation (DNRF121). These funding sources were not involved in the design, data collection, data analysis, and manuscript preparation and/or publication decisions.

\section{Conflicts of Interest}

SB is the codeveloper of the software app Navigate Pain, which was used to collect the pain drawings. SB has company holdings in Aglance Solutions ApS, which licenses a web application of Navigate Pain. Other authors report no conflicts of interest.

\section{Multimedia Appendix 1}

Jaccard indices for each individual patient $(n=59)$ with nonmalignant chronic spinal referred pain in cervical or thoracic and low back (gray) and the group average (black) showing the degree of similarity between 2 consecutive weekly pain and discomfort drawings over the 12 weeks.

[PNG File, 164 KB-Multimedia Appendix 1]

\section{Multimedia Appendix 2}

Example of individual pain drawings showing different drawing behaviors following the delivery of the same instructions. [PNG File, $220 \mathrm{~KB}$-Multimedia Appendix 2]

\section{References}

1. Izzo R, Popolizio T, D'Aprile P, Muto M. Spinal pain. Eur J Radiol 2015 May;84(5):746-756. [doi: 10.1016/j.ejrad.2015.01.018] [Medline: 25824642]

2. Ferreira ML, de Luca K. Spinal pain and its impact on older people. Best Pract Res Clin Rheumatol 2017 Apr;31(2):192-202. [doi: 10.1016/j.berh.2017.08.006] [Medline: 29224696]

3. Jordan KP, Kadam UT, Hayward R, Porcheret M, Young C, Croft P. Annual consultation prevalence of regional musculoskeletal problems in primary care: an observational study. BMC Musculoskelet Disord 2010 Jul 2;11:144 [FREE Full text] [doi: 10.1186/1471-2474-11-144] [Medline: 20598124]

4. Hurwitz EL, Randhawa K, Yu H, Côté P, Haldeman S. The global spine care initiative: a summary of the global burden of low back and neck pain studies. Eur Spine J 2018 Sep;27(Suppl 6):796-801. [doi: 10.1007/s00586-017-5432-9] [Medline: 29480409]

5. Hoy D, Bain C, Williams G, March L, Brooks P, Blyth F, et al. A systematic review of the global prevalence of low back pain. Arthritis Rheum 2012 Jun;64(6):2028-2037 [FREE Full text] [doi: 10.1002/art.34347] [Medline: 22231424]

6. Hartvigsen J, Hancock MJ, Kongsted A, Louw Q, Ferreira ML, Genevay S, Lancet Low Back Pain Series Working Group. What low back pain is and why we need to pay attention. Lancet 2018 Jun 9;391(10137):2356-2367. [doi: 10.1016/S0140-6736(18)30480-X] [Medline: 29573870] 
7. GBD 2017 Disease and Injury Incidence and Prevalence Collaborators. Global, regional, and national incidence, prevalence, and years lived with disability for 354 diseases and injuries for 195 countries and territories, 1990-2017: a systematic analysis for the Global Burden of Disease Study 2017. Lancet 2018 Nov 10;392(10159):1789-1858 [FREE Full text] [doi: 10.1016/S0140-6736(18)32279-7] [Medline: 30496104]

8. IASP Terminology. IASP. 2017. URL: https://www.iasp-pain.org/terminology?navItemNumber=576 [accessed 2019-12-10]

9. Dworkin RH, Turk DC, Farrar JT, Haythornthwaite JA, Jensen MP, Katz NP, IMMPACT. Core outcome measures for chronic pain clinical trials: IMMPACT recommendations. Pain 2005 Jan;113(1-2):9-19. [doi: 10.1016/j.pain.2004.09.012] [Medline: 15621359 ]

10. Boudreau SA, Royo AC, Matthews M, Graven-Nielsen T, Kamavuako EN, Slabaugh G, et al. Distinct patterns of variation in the distribution of knee pain. Sci Rep 2018 Nov 8;8(1):16522 [FREE Full text] [doi: 10.1038/s41598-018-34950-2] [Medline: $\underline{30410031]}$

11. Cruder C, Falla D, Mangili F, Azzimonti L, Araújo LS, Williamon A, et al. Profiling the location and extent of musicians' pain using digital pain drawings. Pain Pract 2018 Jan;18(1):53-66 [FREE Full text] [doi: 10.1111/papr.12581] [Medline: 28466572]

12. Shaballout N, Aloumar A, Neubert T, Dusch M, Beissner F. Digital pain drawings can improve doctors' understanding of acute pain patients: survey and pain drawing analysis. JMIR Mhealth Uhealth 2019 Jan 10;7(1):e11412 [FREE Full text] [doi: 10.2196/11412] [Medline: 30632970]

13. Barbero M, Moresi F, Leoni D, Gatti R, Egloff M, Falla D. Test-retest reliability of pain extent and pain location using a novel method for pain drawing analysis. Eur J Pain 2015 Sep;19(8):1129-1138. [doi: 10.1002/ejp.636] [Medline: 25565607]

14. Shiffman S, Stone AA, Hufford MR. Ecological momentary assessment. Annu Rev Clin Psychol 2008;4:1-32. [doi: 10.1146/annurev.clinpsy.3.022806.091415] [Medline: 18509902]

15. May M, Junghaenel DU, Ono M, Stone AA, Schneider S. Ecological momentary assessment methodology in chronic pain research: a systematic review. J Pain 2018 Jul;19(7):699-716 [FREE Full text] [doi: 10.1016/j.jpain.2018.01.006] [Medline: 29371113]

16. Ono M, Schneider S, Junghaenel DU, Stone AA. What affects the completion of ecological momentary assessments in chronic pain research? An individual patient data meta-analysis. J Med Internet Res 2019 Feb 5;21(2):e11398 [FREE Full text] [doi: 10.2196/11398] [Medline: 30720437]

17. Palmer H. Pain charts; a description of a technique whereby functional pain may be diagnosed from organic pain. N Z Med J 1949 Apr;48(264):187-213. [Medline: 18138692]

18. Toomingas A. Characteristics of pain drawings in the neck-shoulder region among the working population. Int Arch Occup Environ Health 1999 Mar;72(2):98-106. [doi: 10.1007/s004200050344] [Medline: 10197481]

19. Brismar H, Vucetic N, Svensson O. Pain patterns in lumbar disc hernia Drawings compared to surgical findings in 159 patients. Acta Orthop Scand 1996 Oct;67(5):470-472. [doi: 10.3109/17453679608996670] [Medline: $\underline{\text { 8948252] }}$

20. Mann NH, Brown MD, Enger I. Statistical diagnosis of lumbar spine disorders using computerized patient pain drawings. Comput Biol Med 1991;21(6):383-397. [doi: 10.1016/0010-4825(91)90040-g] [Medline: 1838724]

21. Ohnmeiss DD, Vanharanta H, Ekholm J. Relation between pain location and disc pathology: a study of pain drawings and CT/discography. Clin J Pain 1999 Sep;15(3):210-217. [doi: 10.1097/00002508-199909000-00008] [Medline: 10524474]

22. Landmark T, Dale O, Romundstad P, Woodhouse A, Kaasa S, Borchgrevink PC. Development and course of chronic pain over 4 years in the general population: the HUNT pain study. Eur J Pain 2018 Oct;22(9):1606-1616. [doi: 10.1002/ejp.1243] [Medline: 29754398]

23. Vasseljen O, Woodhouse A, Bjørngaard JH, Leivseth L. Natural course of acute neck and low back pain in the general population: the HUNT study. Pain 2013 Aug;154(8):1237-1244. [doi: 10.1016/j.pain.2013.03.032] [Medline: 23664654]

24. Artus M, van der Windt D, Jordan KP, Croft PR. The clinical course of low back pain: a meta-analysis comparing outcomes in randomised clinical trials (RCTs) and observational studies. BMC Musculoskelet Disord 2014 Mar 7;15:68 [FREE Full text] [doi: 10.1186/1471-2474-15-68] [Medline: 24607083]

25. Vos CJ, Verhagen AP, Passchier J, Koes BW. Clinical course and prognostic factors in acute neck pain: an inception cohort study in general practice. Pain Med 2008;9(5):572-580. [doi: 10.1111/j.1526-4637.2008.00456.x] [Medline: 18565009]

26. Enthoven P, Skargren E, Oberg B. Clinical course in patients seeking primary care for back or neck pain: a prospective 5-year follow-up of outcome and health care consumption with subgroup analysis. Spine (Phila Pa 1976) 2004 Nov 1;29(21):2458-2465. [doi: 10.1097/01.brs.0000143025.84471.79] [Medline: 15507811]

27. Artus M, van der Windt DA, Jordan KP, Hay EM. Low back pain symptoms show a similar pattern of improvement following a wide range of primary care treatments: a systematic review of randomized clinical trials. Rheumatology (Oxford) 2010 Dec;49(12):2346-2356. [doi: 10.1093/rheumatology/keq245] [Medline: 20713495]

28. Tesarz J, Gerhardt A, Hartmann M, Kohlmann T, Eich W. The course of the spatial extent of pain in nonspecific chronic back pain: a prospective population-based cohort study with clinical evaluation. Clin J Pain 2016 Jul;32(7):580-587. [doi: 10.1097/AJP.0000000000000308] [Medline: 26491937]

29. Gerhardt A, Hartmann M, Blumenstiel K, Tesarz J, Eich W. The prevalence rate and the role of the spatial extent of pain in nonspecific chronic back pain--a population-based study in the south-west of Germany. Pain Med 2014 Jul;15(7):1200-1210. [doi: 10.1111/pme.12286] [Medline: 24341931] 
30. Suso-Ribera C, Castilla D, Zaragozá I, Ribera-Canudas MV, Botella C, García-Palacios A. Validity, reliability, feasibility, and usefulness of pain monitor: a multidimensional smartphone app for daily monitoring of adults with heterogenous chronic pain. Clin J Pain 2018 Oct;34(10):900-908. [doi: 10.1097/AJP.0000000000000618] [Medline: 29659375]

31. Aaron LA, Mancl L, Turner JA, Sawchuk CN, Klein KM. Reasons for missing interviews in the daily electronic assessment of pain, mood, and stress. Pain 2004 Jun;109(3):389-398. [doi: 10.1016/j.pain.2004.02.014] [Medline: 15157700]

32. Brooke J. SUS-a quick and dirty usability scale. In: Usability Evaluation In Industry. London, UK: Taylor \& Francis Group; Jun 11, 1996.

33. Chaudhry BM. No gain without pain: using pain tracking mobile Apps. Mhealth 2016;2:27 [FREE Full text] [doi: 10.21037/mhealth.2016.06.03] [Medline: 28293601]

34. Guillory J, Chang P, Henderson CR, Shengelia R, Lama S, Warmington M, et al. Piloting a text message-based social support intervention for patients with chronic pain: establishing feasibility and preliminary efficacy. Clin J Pain 2015 Jun;31(6):548-556 [FREE Full text] [doi: 10.1097/AJP.0000000000000193] [Medline: 25565587]

35. Lalloo C, Kumbhare D, Stinson JN, Henry JL. Pain-QuILT: clinical feasibility of a web-based visual pain assessment tool in adults with chronic pain. J Med Internet Res 2014 May 12;16(5):e127 [FREE Full text] [doi: 10.2196/jmir.3292] [Medline: 24819478]

36. Lalloo C, Jibb LA, Rivera J, Agarwal A, Stinson JN. 'There's a pain app for that': review of patient-targeted smartphone applications for pain management. Clin J Pain 2015 Jun;31(6):557-563. [doi: 10.1097/AJP.0000000000000171] [Medline: 25370138]

37. Barmettler G, Brawn J, Maleki N, Scrivani S, Burstein R, Becerra L, et al. A new electronic diary tool for mapping and tracking spatial and temporal head pain patterns in migraine. Cephalalgia 2015 Apr;35(5):417-425. [doi: 10.1177/0333102414545892] [Medline: 25143550]

38. de la Vega R, Roset R, Castarlenas E, Sánchez-Rodríguez E, Solé E, Miró J. Development and testing of painometer: a smartphone app to assess pain intensity. J Pain 2014 Oct;15(10):1001-1007. [doi: 10.1016/j.jpain.2014.04.009] [Medline: 24854065]

39. Davis FD. Perceived usefulness, perceived ease of use, and user acceptance of information technology. MIS Q 1989 Sep;13(3):319. [doi: 10.2307/249008]

40. Vernon H. The neck disability index: state-of-the-art, 1991-2008. J Manipulative Physiol Ther 2008 Sep;31(7):491-502. [doi: 10.1016/j.jmpt.2008.08.006] [Medline: 18803999]

41. Fairbank JC, Pynsent PB. The oswestry disability index. Spine (Phila Pa 1976) 2000 Nov 15;25(22):2940-52; discussion 2952. [doi: 10.1097/00007632-200011150-00017] [Medline: 11074683]

42. Khan RS, Ahmed K, Blakeway E, Skapinakis P, Nihoyannopoulos L, Macleod K, et al. Catastrophizing: a predictive factor for postoperative pain. Am J Surg 2011 Jan;201(1):122-131. [doi: 10.1016/j.amjsurg.2010.02.007] [Medline: 20832052]

43. Bierke S, Häner M, Petersen W. Influence of somatization and depressive symptoms on the course of pain within the first year after uncomplicated total knee replacement: a prospective study. Int Orthop 2016 Jul;40(7):1353-1360. [doi: 10.1007/s00264-015-3105-z] [Medline: 26820743]

44. Egsgaard LL, Christensen TS, Petersen IM, Brønnum DS, Boudreau SA. Do gender-specific and high-resolution three dimensional body charts facilitate the communication of pain for women? A quantitative and qualitative study. JMIR Hum Factors 2016 Jul 20;3(2):e19 [FREE Full text] [doi: 10.2196/humanfactors.5693] [Medline: 27440737]

45. Boudreau SA, Badsberg S, Christensen SW, Egsgaard LL. Digital pain drawings: assessing touch-screen technology and 3D body schemas. Clin J Pain 2016 Feb;32(2):139-145. [doi: 10.1097/AJP.0000000000000230] [Medline: 25756558]

46. Boonstra AM, Stewart RE, Köke AJ, Oosterwijk RF, Swaan JL, Schreurs KM, et al. Cut-off points for mild, moderate, and severe pain on the numeric rating scale for pain in patients with chronic musculoskeletal pain: variability and influence of sex and catastrophizing. Front Psychol 2016;7:1466 [FREE Full text] [doi: 10.3389/fpsyg.2016.01466] [Medline: 27746750]

47. Tsze DS, Hirschfeld G, Dayan PS, Bulloch B, von Baeyer CL. Defining no pain, mild, moderate, and severe pain based on the faces pain scale-revised and color analog scale in children with acute pain. Pediatr Emerg Care 2018 Aug;34(8):537-544 [FREE Full text] [doi: 10.1097/PEC.0000000000000791] [Medline: 27228146]

48. Boudreau SA, Kamavuako EN, Rathleff MS. Distribution and symmetrical patellofemoral pain patterns as revealed by high-resolution 3D body mapping: a cross-sectional study. BMC Musculoskelet Disord 2017 Apr 18;18(1):160 [FREE Full text] [doi: 10.1186/s12891-017-1521-5] [Medline: 28420379]

49. Baron R, Binder A, Wasner G. Neuropathic pain: diagnosis, pathophysiological mechanisms, and treatment. Lancet Neurol 2010 Aug;9(8):807-819. [doi: 10.1016/S1474-4422(10)70143-5] [Medline: 20650402]

50. Bouhassira D, Attal N, Fermanian J, Alchaar H, Gautron M, Masquelier E, et al. Development and validation of the Neuropathic Pain Symptom Inventory. Pain 2004 Apr;108(3):248-257. [doi: 10.1016/j.pain.2003.12.024] [Medline: 15030944]

51. Bouhassira D, Attal N, Alchaar H, Boureau F, Brochet B, Bruxelle J, et al. Comparison of pain syndromes associated with nervous or somatic lesions and development of a new neuropathic pain diagnostic questionnaire (DN4). Pain 2005 Mar;114(1-2):29-36. [doi: 10.1016/j.pain.2004.12.010] [Medline: 15733628]

52. van Hecke O, Kamerman PR, Attal N, Baron R, Bjornsdottir G, Bennett DL, et al. Neuropathic pain phenotyping by international consensus (NeuroPPIC) for genetic studies: a NeuPSIG systematic review, Delphi survey, and expert panel 
recommendations. Pain 2015 Nov;156(11):2337-2353 [FREE Full text] [doi: 10.1097/j.pain.0000000000000335] [Medline: 26469320]

53. Sauro J. 5 Ways to Interpret a SUS Score. MeasuringU. URL: https://measuringu.com/interpret-sus-score/ [accessed 2019-04-07]

54. Farrar JT, Young JP, LaMoreaux L, Werth JL, Poole RM. Clinical importance of changes in chronic pain intensity measured on an 11-point numerical pain rating scale. Pain 2001 Nov;94(2):149-158. [doi: 10.1016/s0304-3959(01)00349-9] [Medline: $11690728]$

55. Leoni D, Falla D, Heitz C, Capra G, Clijsen R, Egloff M, et al. Test-retest reliability in reporting the pain induced by a pain provocation test: further validation of a novel approach for pain drawing acquisition and analysis. Pain Pract 2017 Feb;17(2):176-184. [doi: 10.1111/papr.12429] [Medline: 26992099]

56. Barbero M, Fernández-de-Las-Peñas C, Palacios-Ceña M, Cescon C, Falla D. Pain extent is associated with pain intensity but not with widespread pressure or thermal pain sensitivity in women with fibromyalgia syndrome. Clin Rheumatol 2017 Jun;36(6):1427-1432. [doi: 10.1007/s10067-017-3557-1] [Medline: 28161767]

57. Miró J, de la Vega R, Tomé-Pires C, Sánchez-Rodríguez E, Castarlenas E, Jensen MP, et al. Pain extent and function in youth with physical disabilities. J Pain Res 2017;10:113-120 [FREE Full text] [doi: 10.2147/JPR.S121590] [Medline: 28115871]

58. Miró J, Gertz KJ, Carter GT, Jensen MP. Pain location and intensity impacts function in persons with myotonic dystrophy type 1 and facioscapulohumeral dystrophy with chronic pain. Muscle Nerve 2014 Jun;49(6):900-905 [FREE Full text] [doi: 10.1002/mus.24079] [Medline: 24415580]

59. Lluch Girbés E, Dueñas L, Barbero M, Falla D, Baert IA, Meeus M, et al. Expanded distribution of pain as a sign of central sensitization in individuals with symptomatic knee osteoarthritis. Phys Ther 2016 Aug;96(8):1196-1207. [doi: 10.2522/ptj.20150492] [Medline: 26939604]

60. Parker H, Wood PL, Main CJ. The use of the pain drawing as a screening measure to predict psychological distress in chronic low back pain. Spine (Phila Pa 1976) 1995 Jan 15;20(2):236-243. [doi: 10.1097/00007632-199501150-00022] [Medline: 7716631]

61. Hildebrandt J, Franz CE, Choroba-Mehnen B, Temme M. The use of pain drawings in screening for psychological involvement in complaints of low-back pain. Spine (Phila Pa 1976) 1988 Jun;13(6):681-685. [Medline: 2972073]

62. Dave AJ, Selzer F, Losina E, Klara KM, Collins JE, Usiskin I, et al. Is there an association between whole-body pain with osteoarthritis-related knee pain, pain catastrophizing, and mental health? Clin Orthop Relat Res 2015 Dec;473(12):3894-3902 [FREE Full text] [doi: 10.1007/s11999-015-4575-4] [Medline: 26443774]

63. Bortsov AV, Platts-Mills TF, Peak DA, Jones JS, Swor RA, Domeier RM, et al. Pain distribution and predictors of widespread pain in the immediate aftermath of motor vehicle collision. Eur J Pain 2013 Sep;17(8):1243-1251 [FREE Full text] [doi: 10.1002/j.1532-2149.2013.00285.x] [Medline: 23335385]

64. Ris I, Barbero M, Falla D, Larsen MH, Kraft MN, Søgaard K, et al. Pain extent is more strongly associated with disability, psychological factors, and neck muscle function in people with non-traumatic versus traumatic chronic neck pain: a cross sectional study. Eur J Phys Rehabil Med 2019 Feb;55(1):71-78 [FREE Full text] [doi: 10.23736/S1973-9087.18.04977-8] [Medline: 30156084]

65. Prins MR, van der Wurff P, Groen GJ. Chronic low back pain patients with accompanying leg pain: the relationship between pain extent and pain intensity, disability and health status. J Back Musculoskelet Rehabil 2013;26(1):55-61. [doi: 10.3233/BMR-2012-00350] [Medline: 23411649]

66. Ohnmeiss DD, Vanharanta H, Estlander AM, Jämsén A. The relationship of disability (Oswestry) and pain drawings to functional testing. Eur Spine J 2000 Jun;9(3):208-212 [FREE Full text] [doi: 10.1007/s005869900118] [Medline: 10905438]

67. Reis F, Guimarães F, Nogueira LC, Meziat-Filho N, Sanchez TA, Wideman T. Association between pain drawing and psychological factors in musculoskeletal chronic pain: A systematic review. Physiother Theory Pract 2019 Jun;35(6):533-542. [doi: 10.1080/09593985.2018.1455122] [Medline: 29659315]

68. Marshall PW, Schabrun S, Knox MF. Physical activity and the mediating effect of fear, depression, anxiety, and catastrophizing on pain related disability in people with chronic low back pain. PLoS One 2017;12(7):e0180788 [FREE Full text] [doi: 10.1371/journal.pone.0180788] [Medline: 28686644]

69. Willett MJ, Siebertz M, Petzke F, Erlenwein J, Rushton A, Soldini E, et al. The extent of pain is associated with signs of central sensitization in patients with hip osteoarthritis. Pain Pract 2020 Mar;20(3):277-288. [doi: 10.1111/papr.12851] [Medline: 31665822 ]

70. Martinez-Calderon J, Struyf F, Meeus M, Luque-Suarez A. The association between pain beliefs and pain intensity and/or disability in people with shoulder pain: A systematic review. Musculoskelet Sci Pract 2018 Oct;37:29-57. [doi: 10.1016/j.msksp.2018.06.010] [Medline: 29980139]

71. Millere A, Kalnberza-Ribule Z, Mezals M, Nulle A, Millere I, Deklava L. Disability, pain catastrophizing and stress coping of patients with low back pain in rehabilitation practice in Latvia. J Back Musculoskelet Rehabil 2020;33(2):323-328. [doi: 10.3233/BMR-170945] [Medline: 31524136] 
72. Wertli MM, Eugster R, Held U, Steurer J, Kofmehl R, Weiser S. Catastrophizing-a prognostic factor for outcome in patients with low back pain: a systematic review. Spine J 2014 Nov 1;14(11):2639-2657. [doi: 10.1016/j.spinee.2014.03.003] [Medline: 24607845]

73. Nijs J, Inghelbrecht E, Daenen L, Hachimi-Idrissi S, Hens L, Willems B, et al. Recruitment bias in chronic pain research: whiplash as a model. Clin Rheumatol 2011 Nov;30(11):1481-1489. [doi: 10.1007/s10067-011-1829-8] [Medline: 21853277]

74. Ranney ML, Duarte C, Baird J, Patry EJ, Green TC. Correlation of digital health use and chronic pain coping strategies. Mhealth 2016;2:35 [FREE Full text] [doi: 10.21037/mhealth.2016.08.05] [Medline: 28293608]

75. Becker KL. Cyberhugs: creating a voice for chronic pain sufferers through technology. Cyberpsychol Behav Soc Netw 2013 Feb;16(2):123-126. [doi: 10.1089/cyber.2012.0361] [Medline: 23276258]

76. Göransson C, Eriksson I, Ziegert K, Wengström Y, Langius-Eklöf A, Brovall M, et al. Testing an app for reporting health concerns-experiences from older people and home care nurses. Int J Older People Nurs 2018 Jun;13(2):e12181 [FREE Full text] [doi: 10.1111/opn.12181] [Medline: 29210218]

77. Stone AA, Broderick JE, Schwartz JE, Shiffman S, Litcher-Kelly L, Calvanese P. Intensive momentary reporting of pain with an electronic diary: reactivity, compliance, and patient satisfaction. Pain 2003 Jul;104(1-2):343-351. [doi: 10.1016/s0304-3959(03)00040-x] [Medline: 12855344]

78. Verkerk K, Luijsterburg PA, Heymans MW, Ronchetti I, Pool-Goudzwaard AL, Miedema HS, et al. Prognosis and course of pain in patients with chronic non-specific low back pain: a 1-year follow-up cohort study. Eur J Pain 2015

Sep;19(8):1101-1110. [doi: 10.1002/ejp.633] [Medline: 25565501]

79. Zhang C, Kjellström H, Ek CH, Bertilson BC. Diagnostic Prediction Using Discomfort Drawings with IBTM. In: Proceedings of the 1st Machine Learning for Healthcare Conference. 2016 Jul Presented at: MLR'16; August 19-20, 2016; Los Angeles, CA, USA p. 226-238 URL: http://proceedings.mlr.press/v56/Zhang16.pdf

\author{
Abbreviations \\ eCAS: electronic Color Analogue Scale \\ EMA: ecological momentary assessment \\ HUX: health care-related usability and acceptance \\ mTAM: modified Technology Acceptance Model \\ NDI: Neck Disability Index \\ NPS: Navigate Pain Specific \\ ODI: Oswestry Disability Index \\ PCS: Pain Catastrophizing Scale \\ SUS: System Usability Scale \\ TAM: Technology Acceptance Model
}

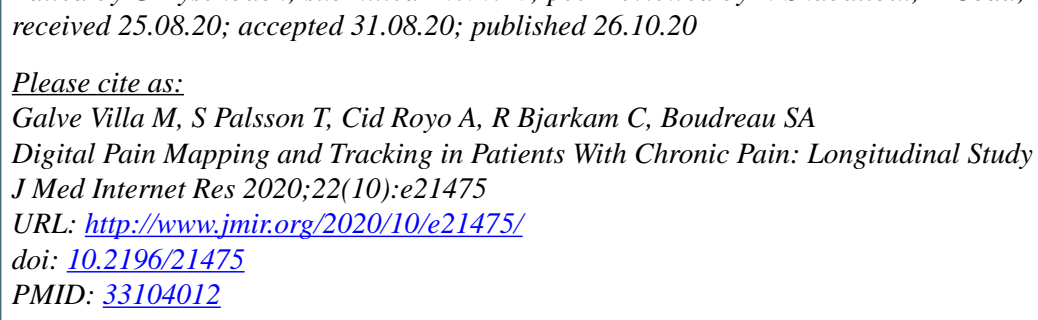

CMaria Galve Villa, Thorvaldur S Palsson, Albert Cid Royo, Carsten R Bjarkam, Shellie A Boudreau. Originally published in the Journal of Medical Internet Research (http://www.jmir.org), 26.10.2020. This is an open-access article distributed under the terms of the Creative Commons Attribution License (https://creativecommons.org/licenses/by/4.0/), which permits unrestricted use, distribution, and reproduction in any medium, provided the original work, first published in the Journal of Medical Internet Research, is properly cited. The complete bibliographic information, a link to the original publication on http://www.jmir.org/, as well as this copyright and license information must be included. 